\title{
Influência do material da ferramenta de corte sobre a usinabilidade do aço ABNT 4340 no torneamento
}

\author{
Influence of cutting tool material on the \\ machinability of ABNT 4340 steel in \\ turning
}

\author{
Bárbara Cristina Mendanha Reis ${ }^{1,2}$, Natália Fernanda Santos Pereira ${ }^{2}$, \\ Anderson Júnior Santos ${ }^{2}$, Marcelo Araújo Câmara ${ }^{2}$, \\ Paulo Eustáquio Faria ${ }^{2}$, Paulo César de Matos Rodrigues ${ }^{2}$, \\ Juan Carlos Campos Rubio ${ }^{2}$
}

\author{
${ }^{1}$ Universidade Federal do Mato Grosso do Sul, Av. Reitor Peró, 79750-000, Nova Andradina, Mato Grosso do Sul, \\ Brasil. \\ ${ }^{2}$ Universidade Federal de Minas Gerais, Av. Presidente Antônio Carlos 6627, CEP: 31270-901, Belo Horizonte, Minas \\ Gerais, Brasil. \\ e-mail: barbara.mendanha@ufms.br,natsantos23@gmail.com,ndersonsantos@hotmail.com, marcelocama- \\ ra@demec.ufmg.br, paulofaria@ufmg.br, paulocmr@demec.ufmg.br, juan@ufmg.br.
}

\begin{abstract}
RESUMO
No presente trabalho procurou-se compreender os fenômenos associados à usinagem do aço ABNT 4340 utilizando ferramentas de corte de metal duro e cermet, ambas com geometria do quebra-cavaco para usinagem leve (LP) e média (MP). Nesse sentido, analisou-se a influência da variação do avanço, quebracavaco e o material da ferramenta de corte nos parâmetros de resposta do processo, força de corte, rugosidade, forma do cavaco e análise das superfícies de saída e de folga dos insertos durante a operação de torneamento. Inicialmente, um planejamento fatorial completo $2^{3}$ foi empregado para análise da força de corte e rugosidade. Em relação à análise da força de corte, a análise de variância (ANOVA) indicou que o material da ferramenta de corte e o avanço afetaram significativamente a força de corte, sendo os menores valores alcançados com a ferramenta de corte cermet e o menor nível de avanço. Quanto à rugosidade $\mathrm{R}_{\mathrm{q}}$, diferentes níveis de materiais de ferramenta ou quebra-cavacos não foram suficientes para alterar significativamente o valor de $\mathrm{R}_{\mathrm{q}}$. Em relação ao cavaco, o avanço e o tipo de quebra-cavaco influenciaram na sua forma. Como última análise, para os parâmetros de corte estabelecidos e percurso de corte, não foi possível identificar desgaste nas ferramentas de corte, no entanto, a análise por EDS apontou a adesão de material nas superfícies de folga e de saída para ambas ferramentas avaliadas.
\end{abstract}

Palavras-chave: aço ABNT 4340. Torneamento. Metal duro. Cermet.

\section{ABSTRACT}

In the present work the aim was to understand the phenomena associated with the machining of ABNT 4340 steel using carbide and cermet cutting tools, both with chipper geometry for light (LP) and medium machining (MP). In this sense, the influence of the variation of the feed rate, the chip breaker and the cutting tool material on the parameters of process response, shear force, shear strength, chip form and analysis of the outlet and gap surfaces of the inserts during the turning operation. Initially, a complete factorial design $2^{3}$ was used for analysis of shear strength and roughness. In relation to the shear force analysis, the analysis of variance (ANOVA) indicated that the cutting tool material and the feed significantly affected the cutting force, the lowest values being obtained with the cermet cutting tool and the lowest level of advancement. As for $\mathrm{R}_{\mathrm{q}}$ roughness, different levels of tool materials or chip breakers were not sufficient to significantly alter the value of $\mathrm{R}_{\mathrm{q}}$. In relation to the chip, the advance and the type of chipbreaker influenced its shape. As a last analysis, it was not possible to identify wear on the cutting tools, for the established cutting parameters and cut path, however, the EDS analysis pointed to the adhesion of material to the clearance and exit surfaces for both tools evaluated. 
Keywords: AISI 4340 steel. Turning. Carbide. Cermet.

\section{INTRODUÇÃO}

Dentre as propriedades desejáveis para um material de ferramenta de corte destacam-se alta dureza, tenacidade para prevenção de falhas por fratura, alta resistência ao desgaste abrasivo, ao choque térmico, ao impacto, à compressão e ao cisalhamento[1], boas propriedades mecânicas e térmicas em altas temperaturas de trabalho [2] e a capacidade de ser inerte quimicamente [3]. As propriedades não se reúnem necessariamente em um só material, mas, de acordo com a aplicação, algumas delas devem ser analisadas [2, 3, 4]. O cermet é considerado um material promissor [5,6] porque, devido a modificações em sua composição química, e/ou métodos de sinterização, vêm apresentando melhorias em propriedades como aumento da dureza em concomitante balanço à tenacidade [5], aumento da temperatura de fusão [6], aumento da condutividade térmica [7] e por fim elevação da resistência à oxidação e a resistência à deformação [8], permitindo melhorias na vida da ferramenta de corte e resistência ao desgaste sob condição de corte com fluidos, quando comparado à ferramenta de metal duro[9, 10].

Anthony [11] avaliou a influência da velocidade de corte $\left(\mathrm{v}_{\mathrm{c}}\right)$, profundidade de usinagem $\left(\mathrm{a}_{\mathrm{p}}\right)$, geometria dos insertos e material da ferramenta de corte sobre o torneamento do aço AISI D2 com dureza de 595 HV. Por meio da análise de variância, o autor verificou que ap tem mais influência na força de corte, seguida por $\mathrm{v}_{\mathrm{c}}$. Com o aumento do ap, mais contato há entre a ferramenta e a peça de trabalho, resultando no aumento da força necessária para completar a operação de corte. Acima de $120 \mathrm{~m} / \mathrm{min}$, ocorreu um rápido aumento da força de corte para qualquer profundidade de usinagem devido a uma maior área de contato. À medida que o raio de ponta aumentou, a área de contato entre a ferramenta e a peça de trabalho foi ampliada, o que resultou em um maior atritoe aumentou, por conseguinte, a força de corte. Em um experimento no qual o aço A192 com dureza de $446 \mathrm{HV}$ foi torneado em condições de corte a seco, Kumar et al. [6] investigaram a influência da concentração de carboneto de tungstênio ( $0-15 \%$ peso) sobre o desgaste ferramenta de cermet com a composição de TiCN-20\%Ni. Com o aumento da velocidade de corte e do avanço, a força de corte inicialmente diminuiu para todos os cermets. Os autores afirmaram que, para velocidades de corte mais baixas, ocorria somente o sulcamento do material da peça, resultando em maior força de corte. Com o aumento da velocidade de corte e do avanço, o corte tornou-se estável, com a consequente redução na força de corte. Os autores acreditam que o aumento da força de corte acima de $74 \mathrm{~m} / \mathrm{min}$ ou 0,11 $\mathrm{mm} / \mathrm{rev}$, deveu-se à degradação térmica da ferramenta de corte e à alteração da geometria do raio de ponta da ferramenta.

CHEN et al. [12] investigaram a qualidade superficial obtida após o corte com ferramenta de metal duro revestida e com cermet sem revestimento. Os autores perceberam que os resultados usando metal duro foram ligeiramente melhores que para o cermet, condição atribuída à elevada resistência à adesão dos revestimentos quando o atrito ocorre entre a superfície recém-formada da peça e a superfície de folga da ferramenta. Com a continuidade do processo de corte, as ferramentas foram sendo desgastadas e as suas geometrias se modificaram. Consequentemente, o valor de desvio aritmético médio $\left(\mathrm{R}_{\mathrm{a}}\right)$ da superfície usinada aumentou gradualmente para as duas ferramentas de maneira exponencial; entretanto, este aumento foi mais rápido para a ferramenta de metal duro revestido. Os autores explicaram que, inicialmente, os menores valores de $\mathrm{R}_{\mathrm{a}}$ obtidos para a superfície torneada com metal duro revestido foram devidos ao efeito dos revestimentos na fase inicial. Ao longo da operação, os revestimentos foram desgastados, o substrato de WCCo ficou exposto, levando à deterioração da ferramenta e à formação de aresta postiça de corte na superfície de folga, resultando em declínio da qualidade da superfície [12]. Já no torneamento de aço inoxidável com ferramenta cermet à base de $\mathrm{Ti}\left(\mathrm{C}_{7} \mathrm{~N}_{3}\right) / \mathrm{WC} / \mathrm{TaC}$ apresentou [13] um aumento do valor da rugosidade com o aumento das taxas de desgaste de flanco, uma vez que a mesma tornou-se estável após o desgaste acelerado da ferramenta, porém, ampliada no momento da falha catastrófica. Keblouti et al. [14] comparando os efeitos dos parâmetros de corte na rugosidade no torneamento do aço AISI 52100 com dureza de $242 \mathrm{HV}$ perceberam que $93,97 \%$ da variação de $\mathrm{R}_{\mathrm{a}}$ quando se usinou com metal duro revestido era explicado pela modificação do avanço enquanto que para o cermet não revestido essa percentagem era de 82,09\%.

$\mathrm{O}$ segundo fator que interferiu na qualidade da superfície foi a $\mathrm{v}_{\mathrm{c}}$, contribuindo para a variação da qualidade superficial em $2,32 \%$ e $7,41 \%$ para inserto revestido e não revestido, respectivamente. Por fim, o $a_{p}$ apresentou pouca influência sobre a rugosidade da superfície, com contribuição inferior a $2 \%$, para ambas ferramentas de corte.

ASTAKHOV [15] ressalta que o desgaste da ferramenta não depende somente do tempo de corte ou do seu percurso, mas também da geometria da ferramenta, regime de corte, propriedades do material da 
peça e muitos outros parâmetros do sistema de usinagem. Nesse sentido, ao se comparar o desempenho de cermets com distintas proporções $\mathrm{WC} / \mathrm{TiCN}, \mathrm{Co} / \mathrm{Ni}$ e $\mathrm{C} / \mathrm{N}$ em solução sólida de $\mathrm{TiCN}$, no torneamento do aço carbono com dureza de $295 \mathrm{HV}$ Zhang et al. [16] verificaram que quando a relação WC/TiCN era inferior a 0,30, o cermet apresentou baixas dureza e resistência à ruptura transversal, e isso conduziu ao desgaste de flanco elevado. Com a proporção $\mathrm{WC} / \mathrm{TiCN}$ superior a 0,30, a ferramenta cermet também apresentou alto desgaste de flanco, embora a sua dureza tenha aumentado com a elevação de WC/TiCN. Em relação à proporção dos ligantes $\mathrm{Co} / \mathrm{Ni}$, inicialmente o aumento da razão diminui o desgaste, mas, quando a proporção superou 2,0 o desgaste aumentou. A baixa resistência ao desgaste do cermet com razão Co/Ni inferior a 2,0 deve-se à baixa dureza e resistência à ruptura transversal. Por fim, os autores verificaram que a solução sólida $\mathrm{TiC}_{0.5} \mathrm{~N}_{0.5}$ tem uma maior resistência ao desgaste de flanco. Diminuindo-se a relação $\mathrm{C} / \mathrm{N}$ em solução sólida no TiCN, aumenta-se a resistência à difusão e oxidação. Isso está de acordo com o acúmulo de calor da ferramenta, o qual depende da condutividade térmica. Os cermets com $\mathrm{C} / \mathrm{N} \geq 1$, tal como $\operatorname{TiC}_{0.7} \mathrm{~N}_{0.3} \mathrm{e}$ $\mathrm{TiC}_{0.6} \mathrm{~N}_{0.4}$, apresentaram uma baixa condutividade térmica, assim, a oxidação tornou-se mais fácil nas fases duras, ricas em Carbono, quando comparadas com aquelas ricas em Nitrogênio.

Em outro trabalho, no torneamento de aço AISI 1045 com dureza de $150 \mathrm{HV}$, variou-se a velocidade de corte em 400, 500 e $600 \mathrm{~m} / \mathrm{min}$ e submeteu-se três insertos aos ensaios de corte: cermet não revestido, metal duro com revestimento triplo $\left(\mathrm{TiN}, \mathrm{Al}_{2} \mathrm{O}_{3}\right.$ e $\left.\mathrm{Ti}(\mathrm{N}, \mathrm{C})\right)$ e metal duro com revestimento duplo $(\mathrm{Ti}(\mathrm{C}, \mathrm{N})$ e $\mathrm{Al}_{2} \mathrm{O}_{3}$ ) com espessuras de 15 e $10 \mu \mathrm{m}$, respectivamente [16]. Para velocidade de corte $600 \mathrm{~m} / \mathrm{min}$ observou-se falha catastrófica e para velocidade de corte de $500 \mathrm{~m} / \mathrm{min}$ desgaste intenso para os inserto de cermet e metal duro com duplo revestimento. Empregando a velocidade de corte de $400 \mathrm{~m} / \mathrm{min}$, o inserto de cermet alcançou o critério de fim de vida muito antes de terminar o tempo de usinagem final, o qual foi estabelecido como 10 minutos. Porém, os insertos de metal duro não alcançaram os critérios de fim de vida quando o limite estabelecido foi alcançado. Para a velocidade de corte de $500 \mathrm{~m} / \mathrm{min}$, tanto o cermet quanto o metal duro com revestimento duplo chegaram ao critério de fim de vida de desgaste de flanco $\left(\mathrm{VB}_{\mathrm{B}}=0,2\right.$ $\mathrm{mm}$ ) antes do tempo de usinagem final de 5 minutos. Para a velocidade de corte de $600 \mathrm{~m} / \mathrm{min}$, o melhor comportamento em relação à tendência de desgaste foi, também, para o inserto de metal duro com revestimento triplo. Entretanto, a ferramenta de cermet apresentou o melhor comportamento em relação à tendência de desgaste, quando comparada ao metal duro com revestimento duplo, devido ao fato que, quando este último perdeu suas camadas de revestimento, o substrato ficou desprotegido e o desgaste cresceu intensamente [16].

Diante do cenário exposto, o objetivo desta pesquisa foi analisar os efeitos da variação do material da ferramenta de corte, da geometria de quebra-cavaco e do avanço de usinagem sobre a força de corte, rugosidade, forma do cavaco e análise das superfícies de folga e saída, durante o torneamento do aço ABNT 4340.

\section{MATERIAIS E MÉTODOS}

Os experimentos foram realizados conforme o fluxograma apresentado na Figura 1. 


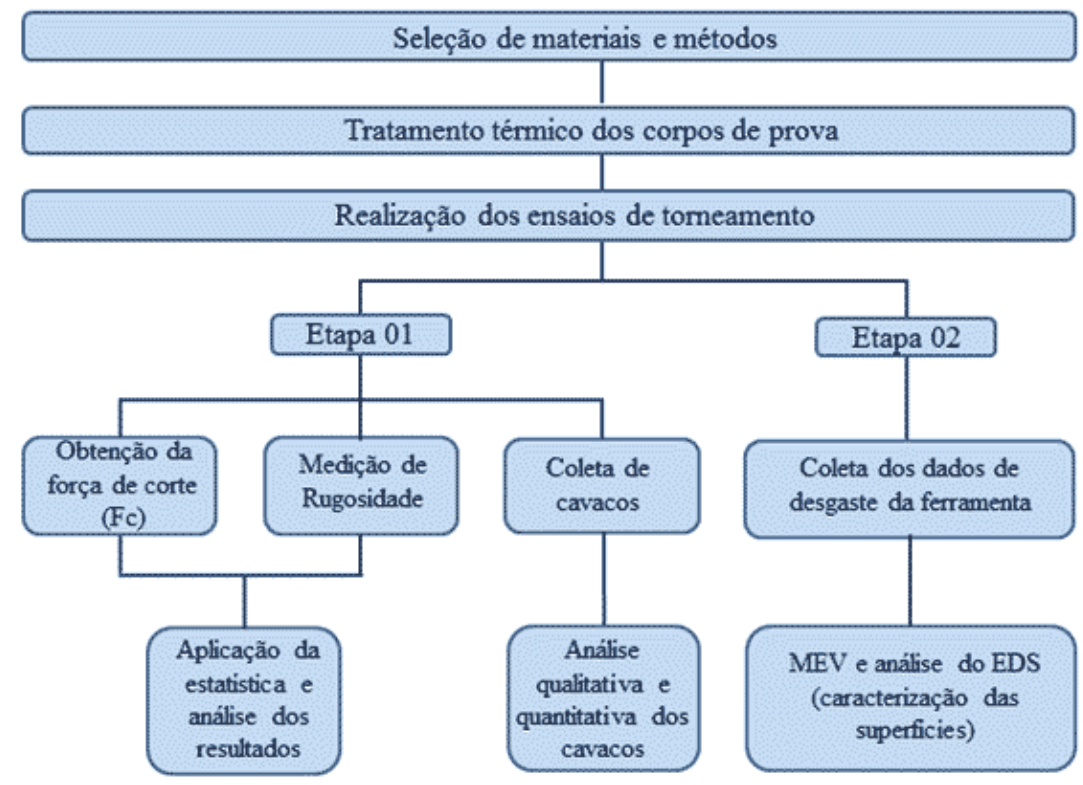

Figura 1: fluxograma do procedimento experimental.

Os corpos de prova, na forma de barras cilíndricas, utilizados neste estudo foram confeccionados em aço ABNT 4340 com diâmetro inicial de $78 \mathrm{~mm}$ e comprimento de $300 \mathrm{~mm}$. A fim de homogeneizá-los, os corpos de prova foram recozidos a uma temperatura de $690{ }^{\circ} \mathrm{C}$ por quatro horas e resfriados ao forno até atingir a temperatura ambiente, indicando uma dureza final de $233 \mathrm{HV}$ A composição química deste aço pode ser vista na Tabela 1 , sendo que estes valores foram extraídos da corrida 008467303.

Tabela 1: Composição química do aço ABNT 4340

\begin{tabular}{c|c|c|c|c|c|c|c|c|c|c}
\hline Elemento Químico & $\mathrm{C}$ & $\mathrm{Si}$ & $\mathrm{Mn}$ & $\mathrm{P}$ & $\mathrm{S}$ & $\mathrm{Cr}$ & $\mathrm{Cu}$ & $\mathrm{Mo}$ & $\mathrm{Ni}$ & $\mathrm{Al}$ \\
\hline Composição (\%) & 0,39 & 0,24 & 0,74 & 0,01 & 0,006 & 0,77 & 0,01 & 0,22 & 1,72 & 0,02 \\
\hline
\end{tabular}

Fonte: Açolíver (2016).

Para o torneamento a seco do aço ABNT 4340, utilizou-se um torno Romi modelo Centur 30s (5,5 kW de potência e rotação máxima de $3500 \mathrm{rpm}$ ), com um suporte de ferramenta PCLNR 2020K-12, juntamente com as ferramentas de corte de metal duro e de cermet, cada uma com duas geometrias de quebracavaco distintas: leve usinagem (LP) e média usinagem (MP), códigos CNMG120408LP e CNMG120408MP, respectivamente, conforme ilustrado pela Figura 2. 


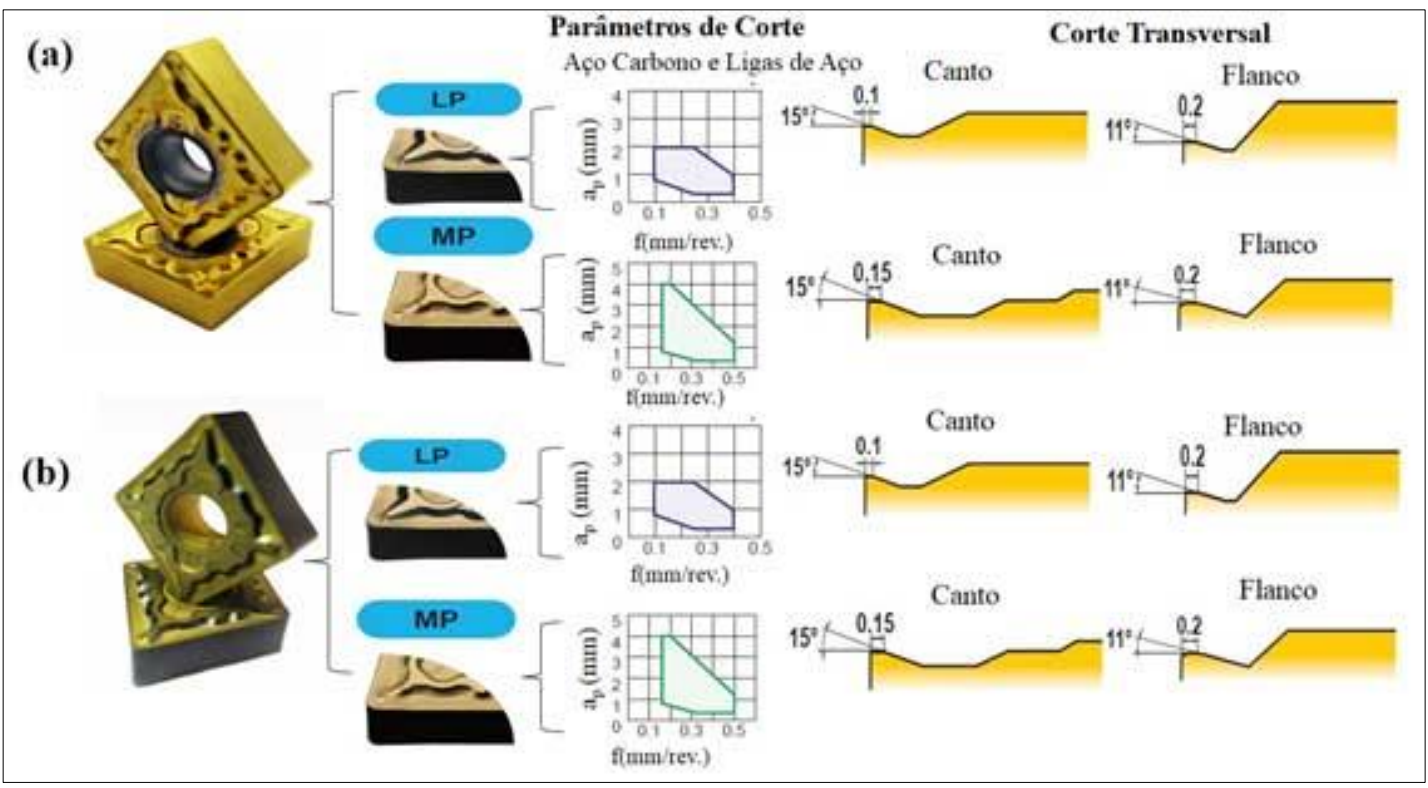

Figura 2: insertos utilizados para torneamento (a) cermet (b) metal duro. Fonte: adaptado de Mitsubishi (2015).

Comparando as propriedades físicas do cermet e do metal duro, Tabela 2, destaca-se a diferença da condutividade térmica e a dureza desses dois materiais. Em relação à condutividade térmica verifica-se que o cermet apresenta cerca de $12 \%$ do valor desta propriedade quando comparado ao metal duro, ou seja, $0,052\left(\mathrm{cal} / \mathrm{cm} \mathrm{s}^{\circ} \mathrm{C}\right)$ e $0,42\left(\mathrm{cal} / \mathrm{cm} \mathrm{s}{ }^{\circ} \mathrm{C}\right)$, respectivamente [3]. A resistência à penetração, o fabricante das ferramentas [22] ressalta que o carboneto de tungstênio (WC), principal componente do substrato do metal duro, apresenta uma dureza de 1780 HV, enquanto o carboneto de titânio (TiC) 3200 HV.

Tabela 2: Comparação das propriedades físicas do cermet (TiC) com o metal duro (WC)

\begin{tabular}{|c|c|c|c|c|c|}
\hline Propriedades Físicas & Cermet & Metal Duro & Propriedades Físicas & Cermet & Metal Duro \\
\hline Dureza (HV) & 3200 & 2100 & $\begin{array}{l}\text { Condutividade térmica } \\
\left(\mathrm{cal} / \mathrm{cm} \mathrm{s}^{\circ} \mathrm{C}\right)\end{array}$ & 0,052 & 0,42 \\
\hline $\begin{array}{l}\text { Energia livre de formação } \\
\quad\left(\mathrm{kcal} / \mathrm{g} \text { - atm } 1000^{\circ} \mathrm{C}\right)\end{array}$ & -35 & -10 & $\begin{array}{l}\text { Coeficiente de dilatação } \\
\text { térmica }\left(10^{-6} /{ }^{\circ} \mathrm{C}\right)\end{array}$ & 7,2 & 5,2 \\
\hline $\begin{array}{l}\text { Solubilidade no ferro } \\
\quad\left(w t \% \text { a } 1250^{\circ} \mathrm{C}\right)\end{array}$ & 0,5 & 7 & $\begin{array}{l}\text { Coeficiente de choque } \\
\text { térmico* }\end{array}$ & 1,9 & 27,1 \\
\hline Temperatura de oxidação $\left({ }^{\circ} \mathrm{C}\right)$ & 1100 & 700 & & & \\
\hline
\end{tabular}

Fonte: Machado et al. (2015)

Em relação ao revestimento das ferramentas, a Figura 3 retrata a caracterização dos métodos de deposição, constituintes e espessura da camada revestida na superfície de saída dos insertos acima citados, por meio de MEV e os respectivos EDS. Em relação à superfície de folga, o cermet foi revestido por camada única de nitreto de titânio (TiN) e o metal duro por óxido de alumínio (Al2O3). Ressalta-se que para a caracterização dos revestimentos bem como superfícies de folga e saída dos insertos prresentes neste artigo utilizou-se um microscópio JEOL, modelo JSM-IT300 para microscopia de varredura eletrônica (MEV) e para a espectroscopia de energia dispersiva (EDS) um acessário acoplado a este microscópio da Oxford Instruments, modelo X-MaxN A geração e tratamento dos dados obtidos pelas técnicas de caracterização, utilizou-se o software AZtec. 


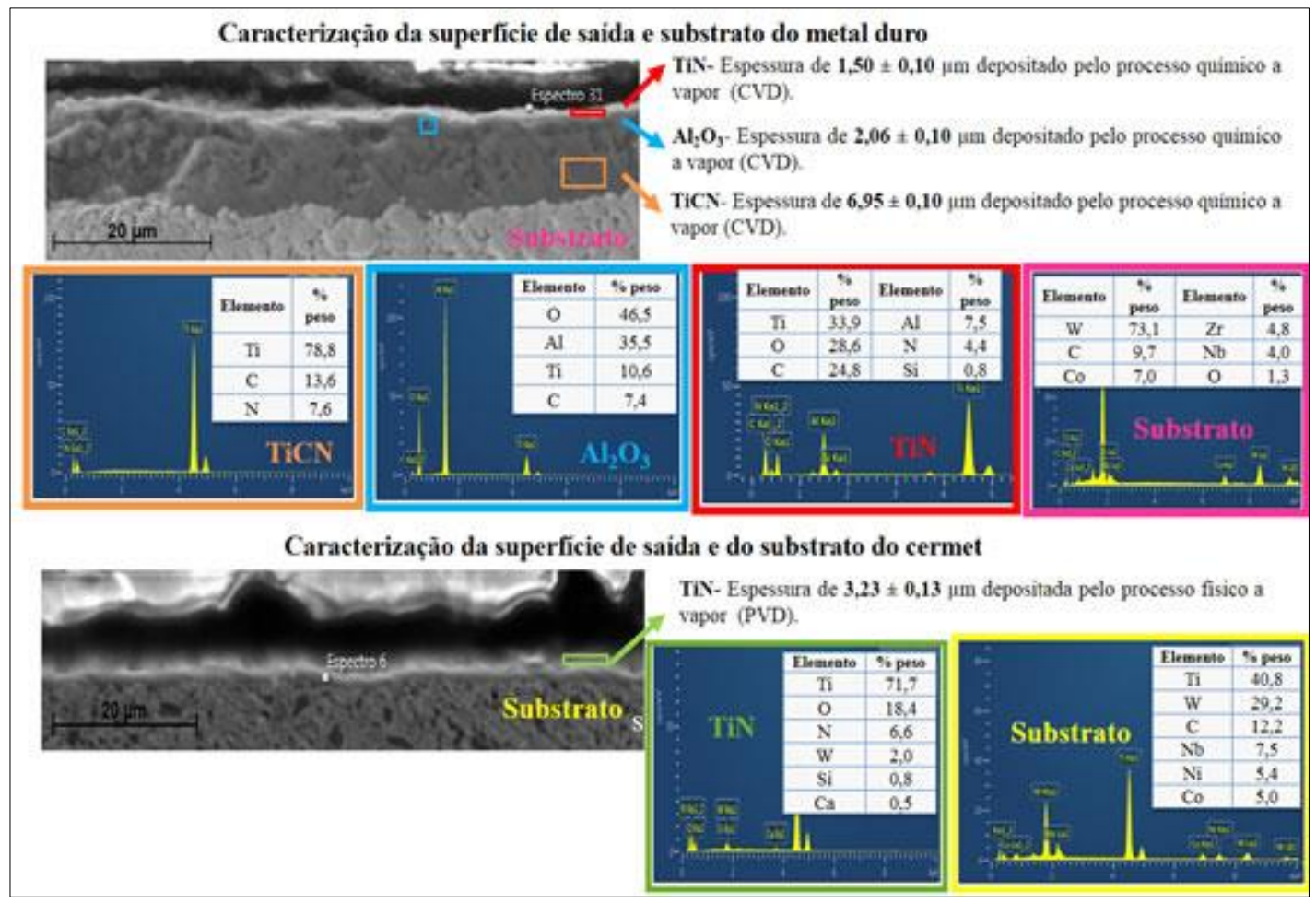

Figura 3: caracterização das camadas de revestimentos e substratos dos insertos de metal duro e cermet

\subsection{Força de corte}

A força de corte foi obtida de forma indireta, por meio da potência elétrica consumida pelo motor do eixo árvore principal do equipamento, a fim de reduzir a variabilidade dos resultados obtidos. A fim de garantir que a rotação da máquina mantivesse constante, $v_{c}$ e $a_{p}$ foram mantidos constantes, porque, uma vez que a obtenção da força de corte deu-se indiretamente, um aumento na $\mathrm{v}_{\mathrm{c}}$, sem o devido ajuste no diâmetro da peça, acarretaria em acréscimo da potência, não pela modificação dos parâmetros de entrada, mas sim pela característica do equipamento. $\mathrm{O}$ fato de $\mathrm{v}_{\mathrm{c}}$ e $\mathrm{a}_{\mathrm{p}}$ terem sido mantidos constantes garantiu a manutenção da mesma relação entre $v_{c}$ e o diâmetro ao longo dos testes, e, por conseguinte, qualquer alteração na corrente consumida foi atribuída ao efeito que a mudança dos parâmetros de entrada gerou.

Para a coleta dos sinais de corrente elétrica consumida durante o teste, um multímetro PoliMed modelo Tru RMS PM-4650, foi conectado ao cabo de alimentação do motor principal por um alicate amperímetro. Pela relação que estabelece que $10 \mathrm{mV}$ no amperímetro equivalem a $1 \mathrm{~A}$, foi possível determinar os dados da corrente elétrica consumida pela operação em cada teste e, assim, determinar a força de corte de forma indireta por meio da Equação 1:

$$
\mathbf{F}_{\mathrm{c}}=\frac{60 \cdot \mathrm{I} \cdot \mathrm{V} \cdot \sqrt{3} \cdot \cos (\varphi) \cdot \eta}{\mathrm{V}_{\mathrm{c}}}
$$

Onde:

$\mathrm{F}_{\mathrm{c}}=$ Força de corte $[\mathrm{N}]$

$\mathrm{I}=$ Corrente consumida $[\mathrm{A}]$

$\mathrm{V}=$ Tensão de alimentação do torno [220 V]

$\operatorname{Cos}(\varphi)=$ Fator de potência $[0,95]$

$\eta=$ Eficiência de transmissão do torno $[0,8]$

$\mathrm{vc}=$ Velocidade de corte $[\mathrm{m} / \mathrm{min}]$ 


\subsection{Rugosidade}

Após cada conjunto de testes realizados, os valores do desvio aritmético médio $\left(R_{a}\right)$ e do desvio médio quadrático $\left(\mathrm{R}_{\mathrm{q}}\right)$ foram medidos com um rugosímetro Mitutoyo, modelo Surftest 301 empregando um cut off de 2,5 mm. A medição de rugosidade ocorreu em três pontos equidistantes da circunferência do corpo de prova, para cada passe de usinagem, e o valor médio foi calculado.

\subsection{Aplicação do método estatístico e análise dos resultados}

Para análise das respostas, Força de corte e Rugosidade, variaram-se material da ferramenta de corte (cermet e metal duro), geometria do quebra-cavaco (LP e MP) e avanço (0,16 e 0,40 mm/rev.), o que resultou num planejamento de experimentos para um fatorial completo $2^{3}$, o que totalizou 16 testes, sendo 8 referentes ao teste principal e os demais à réplica. Dada a necessidade de manutenção constante da relação Vc e diâmetro, uma vez que a força de corte foi obtida indiretamente, nessa etapa, os parâmetros de corte foram mantidos constantes, a dizer: velocidade de corte de $250 \mathrm{~m} / \mathrm{min}$ e profundidade de usinagem de $1,5 \mathrm{~mm}$. O diâmetro inicial de cada barra foi de $78 \mathrm{~mm}$.

Para evitar que fatores não controláveis influenciassem os resultados, os testes foram realizados em ordem aleatória. Para a análise dos resultados, foi empregada o planejamento de experimentos (DOE) e a análise de variância (ANOVA), por meio do software Minitab versão 17. Posteriormente, foi construído o gráfico do valor médio dos parâmetros de saída com o intervalo de confiança de $95 \%$, para possibilitar a comparação entre a influência de cada parâmetro de entrada, bem como as suas interações, sobre a força de corte e a rugosidade.

\subsection{Análise das superfícies de folga e de saída}

Nessa etapa, os parâmetros de corte foram escolhidos de maneira a atender, simultaneamente, os requisitos do fabricante para cada material de ferramenta e geometria de quebra-cavaco. Assim, foram mantidos constantes $\mathrm{Vc}$ de $250 \mathrm{~m} / \mathrm{min}$, f de $0,16 \mathrm{~mm} / \mathrm{rev}$ e $\mathrm{a}_{\mathrm{p}}$ de $1,5 \mathrm{~mm}$, para um comprimento usinado de $1880 \pm 20 \mathrm{~mm}$. A caracterização das superfícies de folga e saída foi realizada pelos mesmos instrumentos descritos na caracterização dos revestimentos.

\section{RESULTADOS}

Os resultados de todos os ensaios realizados neste trabalho serão apresentados na seguinte ordem: força de corte, rugosidade, análise dos cavacos e desgaste da ferramenta de corte. Na análise estatística, considerouse $\alpha=0,05$ para todas as variáveis de resposta, isto é, um intervalo de confiança de $95 \%$.

Antes da realização da análise de variância (ANOVA), foi verificada a adequação do modelo por meio da análise residual. Calculou-se os resíduos por meio do teste de Anderson-Darling, o qual indicou um p-valor de 0,144 para a força de corte e 0,229 para a rugosidade, validando a hipótese de que os dados seguem a distribuição normal para ambas variáveis de saída. Por fim, os gráficos de análise residual apontaram variância constante e resíduos distribuídos aleatoriamente em relação ao tempo. Uma vez comprovada à adequação do modelo, a ANOVA foi realizada com objetivo de verificar a influência dos parâmetros, material da ferramenta de corte, geometria de quebra-cavaco e avanço, além da combinação destas variáveis sobre a força de corte e rugosidade Rq, em um nível de significância de 5\%. A Tabela 3 apresenta a análise de variância para a força de corte e rugosidade, evidenciando os efeitos significativos ao nível de confiança estabelecido.

Tabela 3: ANOVA aplicada nos resultados dos ensaios de força de corte e rugosidade (material da ferramenta de corte, geometria do quebra-cavaco e avanço)

\begin{tabular}{c|c|c|c|c|c|c}
\hline & \multicolumn{3}{|c|}{ Força de Corte } & \multicolumn{3}{c}{ Rugosidade (Rq) } \\
\hline Variáveis & $\begin{array}{c}\text { Soma dos } \\
\text { Quadrados }\end{array}$ & Valor F & p-valor & $\begin{array}{c}\text { Soma dos } \\
\text { Quadrados }\end{array}$ & Valor F & p-valor \\
\hline Material da ferramenta de corte (a) & 813 & 11,73 & $\underline{0,009}$ & 0,068 & 0,19 & 0,671 \\
\hline
\end{tabular}




\begin{tabular}{|c|c|c|c|c|c|c|}
\hline Geometria do quebra-cavaco (b) & 185 & 2,68 & 0,141 & 0,740 & 2,13 & 0,182 \\
\hline Avanço (c) & 760380 & 10971,47 & $\underline{0,000}$ & 230,888 & 665,50 & $\underline{0,000}$ \\
\hline (a)*(b) & 2500 & 36,08 & $\underline{0,000}$ & 0,073 & 0,21 & 0,659 \\
\hline$(\mathrm{a}) *(\mathrm{c})$ & 663 & 9,56 & $\underline{0,015}$ & 0,601 & 1,73 & 0,225 \\
\hline$(\mathrm{b}) *(\mathrm{c})$ & 2718 & 39,21 & $\underline{0,000}$ & 0,024 & 0,07 & 0,799 \\
\hline$(a) *(b) *(c)$ & 26 & 0,38 & 0,556 & 0,081 & 0,23 & 0,641 \\
\hline Erro & 554 & & & 2,775 & & \\
\hline Total & 767840 & & & 767840 & & \\
\hline \multirow{2}{*}{ Sumário do modelo } & $\mathbf{R}^{2}$ & $R^{2}$ (aj) & $\mathbf{R}^{2}$ (pred) & $\mathbf{R}^{2}$ & $\mathbf{R}^{2}$ (aj) & $\mathbf{R}^{2}$ (pred) \\
\hline & $99,93 \%$ & $99,86 \%$ & $99,71 \%$ & $98,82 \%$ & $97,79 \%$ & $95,28 \%$ \\
\hline
\end{tabular}

\subsection{Força de Corte}

Conforme ilustra a Tabela 3, entre os efeitos principais, material da ferramenta de corte e avanço mostraram-se significativos ao nível de significância considerada. Quanto às interações de segunda ordem, todas apresentaram um p-valor menor que 0,05 ; a interação de terceira ordem, por outro lado, mostrou-se não significativa dentro do intervalo de confiança estudado. Logo, é possível constatar que existe uma correlação estatisticamente significativa, ao nível de confiança considerado, entre a mudança no avanço e no material da ferramenta de corte e entre as interações de segunda ordem, para a variação da força de corte. Na Figura 4 está o gráfico de interação de segunda ordem para todas as variáveis de entradas desse planejamento fatorial.

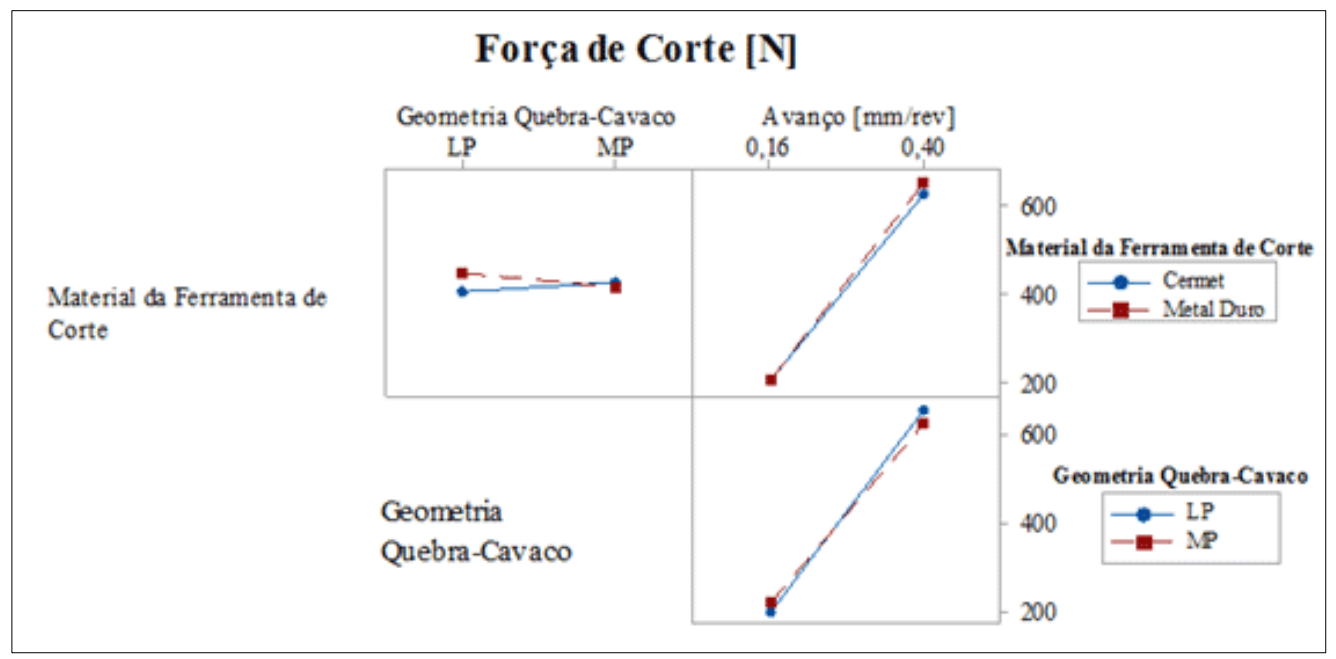

Figura 4: gráfico de interação de segunda ordem para a força de corte (material da ferramenta de corte, geometria do quebra-cavaco e avanço).

Em relação ao material da ferramenta de corte, verificou-se que, para $\mathrm{f}=0,16 \mathrm{~mm} / \mathrm{rev}$, cermet e metal duro apresentam forças de corte médias semelhantes. Para $\mathrm{f}=0,40 \mathrm{~mm} / \mathrm{rev}$, metal duro mostrou força de corte ligeiramente superior ao cermet. Para a interação entre material da ferramenta de corte e geometria do quebra-cavaco, a ferramenta de cermet apresentou o menor valor de força de corte para a configuração LP; já para o quebra-cavaco, MP não é possível diferenciar, dado que foram encontrados valores bem próximos de força de corte. Pressupõe-se que o fato de cermet e do metal duro apresentarem o mesmo revestimento (TiN) e não terem sofrido desgaste aparente durante o corte, contribuiu para que essa diferença na força de corte não fosse maior.

Quando observado o efeito do material da ferramenta de corte, observou-se que, para a geometria de quebra-cavaco LP, o cermet apresentou menor força de corte; já para a geometria MP não foi possível verificar significativa alteração em relação à mudança de material. Ao se considerar o avanço, para $\mathrm{f}=0,16$ $\mathrm{mm} / \mathrm{rev}$, o uso de cermet ou de metal duro não causou modificações significativas na força de corte. Para $\mathrm{f}=0,40 \mathrm{~mm} / \mathrm{rev}$, ocorreu uma sensível redução na força de corte quando a ferramenta de cermet foi utilizada. 
Justificam-se tais comportamentos por meio da menor condutividade térmica do cermet, que levou ao aumento do calor no plano de cisalhamento e consequente efeito de amaciamento. A elevação da temperatura nas zonas de corte primária e secundária, quando se usina com ferramenta de cermet, pode ser benéfica ao diminuir a resistência mecânica do material da peça de trabalho para auxiliar a continuação da deformação plástica e da ruptura do cavaco [3].

Neste estudo, os quebra-cavacos operaram em condições determinadas pelo fabricante, tanto para o avanço quanto para a profundidade de usinagem. Tal condição não permitiu que a força de corte sofresse alterações de maneira significativa. Entretanto, a interação entre a geometria do quebra-cavaco e o avanço mostrou-se significativa, uma vez que, para $\mathrm{f}=0,16 \mathrm{~mm} / \mathrm{rev}$, os valores de força de corte foram bem próximos, mas destacando-se o quebra-cavaco LP com um valor um pouco menor. Para $\mathrm{f}=0,40 \mathrm{~mm} / \mathrm{rev}$, essa diferença já se mostrou maior, confirmando o quebra-cavaco LP com a maior força. O quebra-cavaco LP, está trabalhando em seu limite superior quando empregado $\mathrm{f}=0,40 \mathrm{~mm} / \mathrm{rev}$ e bem próximo de seu maior valor admitido para a profundidade de usinagem. Já o quebra-cavaco MP, opera com folga em relação aos intervalos de trabalho estabelecidos para a profundidade de usinagem e avanço. Logo, pressupõe-se que o maior valor da força de corte deve-se aos rígidos valores estabelecidos para os parâmetros de corte, quando analisadas as recomendações do fabricante.

\subsection{Rugosidade}

Os resultados relativos à rugosidade foram apresentados apenas para $\mathrm{R}_{\mathrm{q}}$, Tabela 3 , visto que foram semelhantes aos resultados e análises realizados para os valores de $\mathrm{R}_{\mathrm{a}}$. Por meio da análise residual é possível afirmar que os erros decorrentes do modelo foram aleatórios e que a regressão gerada pela ANOVA pode ser confirmada, dado que o nível de explicação do modelo para a variação da rugosidade foi de $97,79 \%$. Da Tabela 3 constatou-se que somente o efeito principal do avanço influencia significativamente, ao nível de confiança estabelecido pelo modelo, a rugosidade, uma vez que foi o único parâmetro que apresentou um pvalor inferior a 0,05. Assim, infere-se que nem a mudança no material da ferramenta de corte ou na geometria do quebra-cavaco e nem as interações são suficientes para influenciar significativamente o valor de $R_{q}$. A Figura 5 apresenta os efeitos principais, correlacionando as médias do desvio médio quadrático $\left(\mathrm{R}_{\mathrm{q}}\right)$ com os níveis de cada variável de entrada.

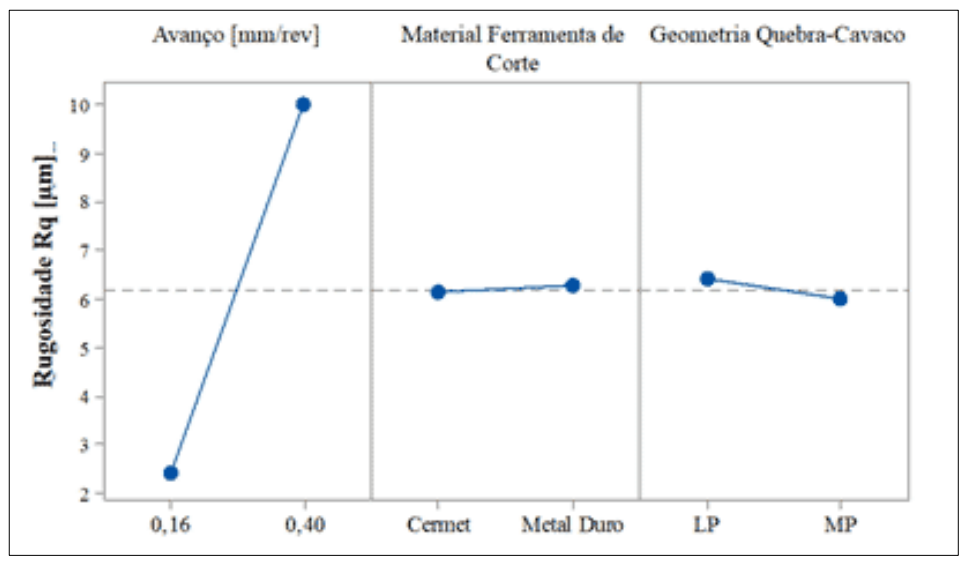

Figura 5: gráfico de efeito principal para $\mathrm{Rq}$ (material da ferramenta de corte, avanço e geometria do quebra-cavaco).

Quanto ao material da ferramenta e à geometria do quebra-cavaco, a curva gerada é pouco inclinada, quase paralela à linha média geral, indicando que tais efeitos principais não foram suficientes para gerar mudanças significativas no $\mathrm{R}_{\mathrm{q}}$, confirmando, assim, a ANOVA realizada anteriormente.

Em relação ao parâmetro avanço, nota-se que a mudança de nível afeta consideravelmente a média de $R_{q}$, sendo a taxa de crescimento semelhante tanto para $f=0,16 \mathrm{~mm} / \mathrm{rev}$ quanto para $\mathrm{f}=0,40 \mathrm{~mm} / \mathrm{rev}$. $\mathrm{O}$ aumento do avanço em cerca de 2,5 vezes levou a um ganho de 5 vezes na rugosidade média da superfície, 
corroborando as discussões de MACHADO et al. [3] que afirmam, dentre as condições de corte, o avanço mostra-se como o parâmetro mais influente, uma vez que a altura média dos vales das marcas de avanço tende a aumentar em proporção quadrática ao avanço.

\subsection{Cavacos}

A Tabela 4 apresenta os cavacos gerados para os diferentes avanços, materiais de ferramentas de corte e geometria de quebra-cavacos testados. De acordo com a classificação estabelecida pela norma ISO 3685[23] os cavacos podem ser caracterizados da seguinte maneira: cavaco em arco conectado para cermet $\mathrm{LP}(\mathrm{f}=0,16 \mathrm{~mm} / \mathrm{rev})$, cermet MP e metal duro MP $(\mathrm{f}=0,40 \mathrm{~mm} / \mathrm{rev})$; cavaco em arco solto para cermet LP ( $\mathrm{f}=0,40 \mathrm{~mm} / \mathrm{rev}$ ), metal duro LP ( $\mathrm{f}=0,16 \mathrm{~mm} / \mathrm{rev}$ e $\mathrm{f}=0,40 \mathrm{~mm} / \mathrm{rev}$ ); cavaco helicoidal curto para metal duro MP (f=0,40 mm/rev); e cavaco fragmentado para cermet $\mathrm{MP}(\mathrm{f}=0,16 \mathrm{~mm} / \mathrm{rev})$.

Tabela 4: imagem dos cavacos coletados $\left(\mathrm{v}_{\mathrm{c}}=250 \mathrm{~m} / \mathrm{min}\right.$ e $\left.\mathrm{a}_{\mathrm{p}}=1,5 \mathrm{~mm}\right)$ 


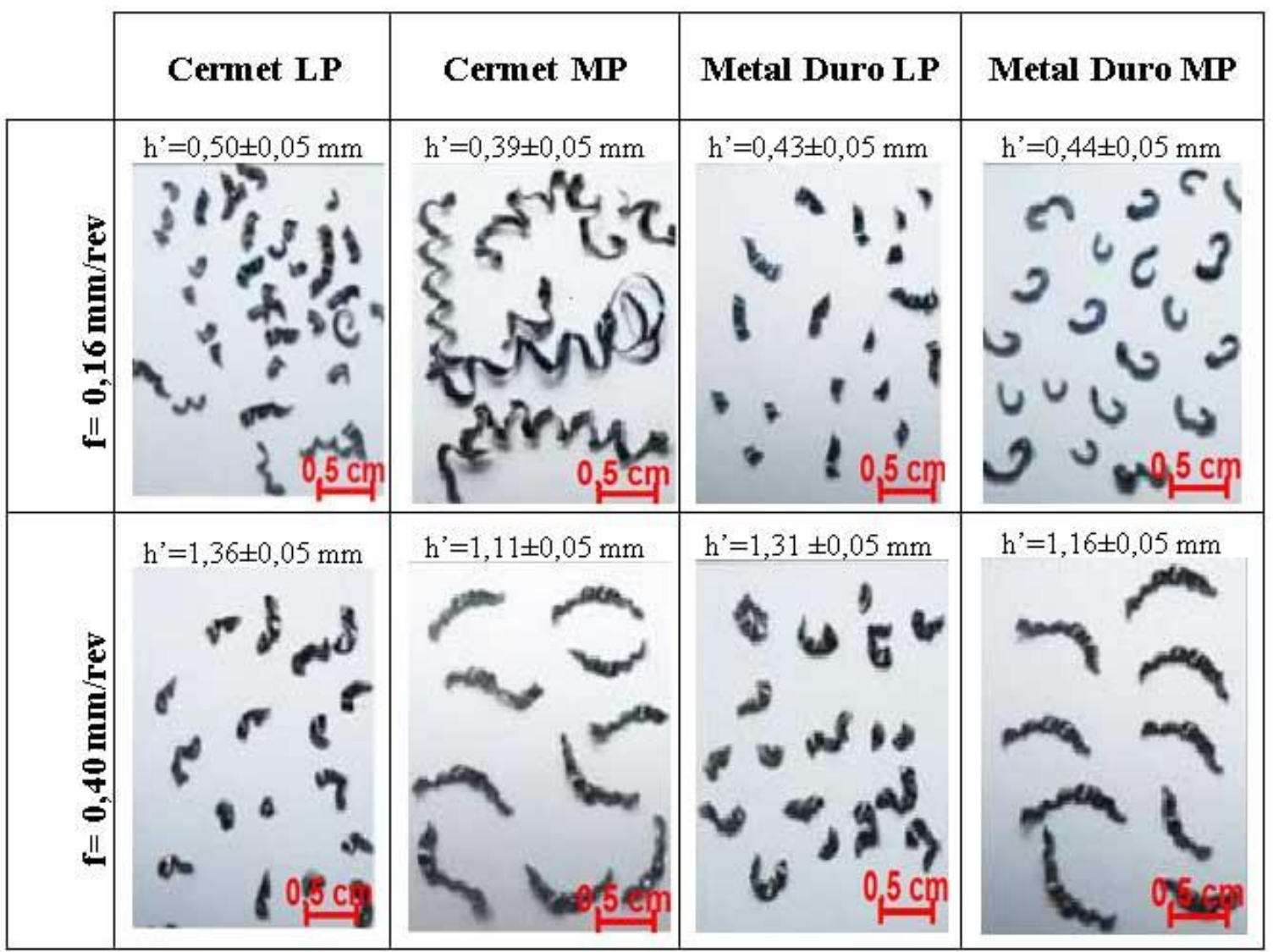

Pode-se observar, na Tabela 4 que o aumento do avanço, levou a alteração da forma do cavaco, iniciando na forma de fita, passando pelo tipo helicoidal, até chegar no cavaco em arco e fragmentado. Observou-se que, para $\mathrm{f}=0,16 \mathrm{~mm} / \mathrm{rev}$, a espessura do cavaco apresentou valores bem inferiores relativo aos obtidos para $\mathrm{f}=0,40 \mathrm{~mm} / \mathrm{rev}$, independentemente do material da ferramenta de corte e do tipo de quebracavaco. Logo, notou-se que a quebra do cavaco foi facilitada pelo aumento da espessura deste (h'), ou seja, do grau de recalque da operação. Quanto menor h', mais flexíveis são os cavacos e, portanto, se tornam mais difíceis para se quebrar.

Em relação à geometria de quebra-cavaco, o tipo MP para o inserto de cermet no avanço de 0,16 $\mathrm{mm} / \mathrm{rev}$ apresentou a forma mais distinta entre as demais. O quebra-cavaco MP apresentou uma maior superfície de contato com o cavaco. Essa característica, associada à baixa condutividade térmica do material, permitiu que grande parte do calor gerado entre o cavaco e a superfície da ferramenta fosse transferida para o cavaco. Menor avanço, pequena h' e o calor, contribuem para a redução da resistência ao cisalhamento e favorecem o aumento da ductibilidade do material, dificultando sua quebra.

\subsection{Análise das superfícies de saída e de folga das ferramentas de corte}

A Tabela 5 contém as imagens das superfícies das ferramentas de corte obtidas por MEV, de maneira a realçar as superfícies de saída e de folga. De maneira geral, não foi possível afirmar a ocorrência de desgaste nem descrever seus possíveis mecanismos. As imagens relacionadas na Tabela 5 não revelaram comportamento superior do inserto de metal duro com revestimento triplo quando comparado ao cermet com camada única de cobertura. Supõe-se que o fato de nenhum inserto ter apresentado desgaste de flanco, cratera ou entalhe sem ao menos evidenciar critérios de fim de vida ou falha catastrófica, deveu-se à pouca distância usinada, associada aos parâmetros de corte estabelecidos para a realização dos testes, que estavam dentro dos intervalos recomendados pelo fabricante.

Tabela 5: imagem das superfícies dos insertos $\left(\mathrm{v}_{\mathrm{c}}=250 \mathrm{~m} / \mathrm{min}, \mathrm{f}=0,16 \mathrm{~mm} / \mathrm{rev}, \mathrm{a}_{\mathrm{p}}=1,5 \mathrm{~mm}\right)$ 


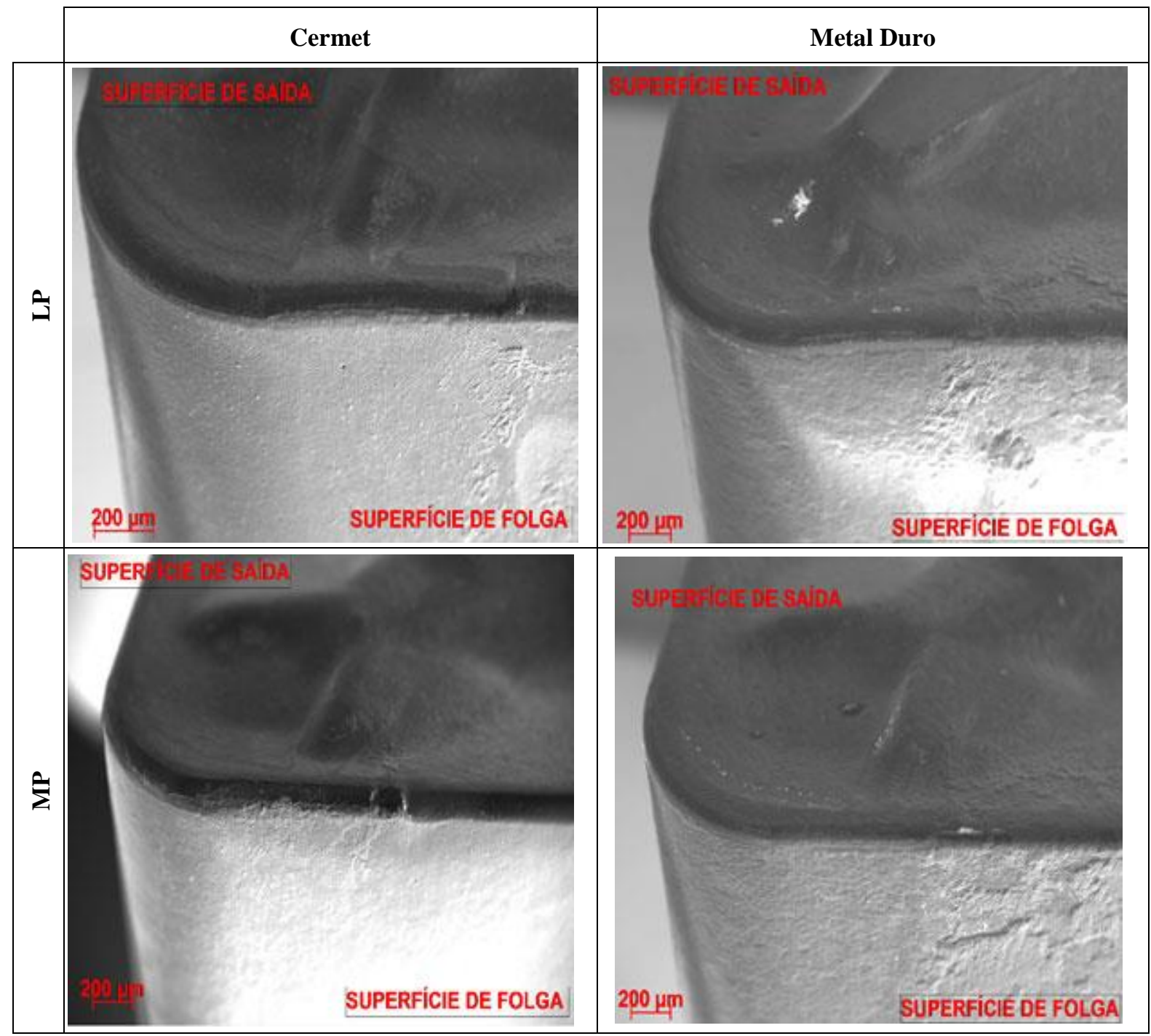

Com objetivo de se verificar a ocorrência de um processo de retirada do revestimento ou adesão de material da peça de aço, nas superfícies de saída e folga dos insertos, foi realizada análise por meio de EDS, conforme imagens organizadas nas Tabelas 6 e 7.

Tabela 6: imagens das superfícies de saída dos insertos e análise EDS $\left(\mathrm{v}_{\mathrm{c}}=250 \mathrm{~m} / \mathrm{min}, \mathrm{f}=0,16 \mathrm{~mm} / \mathrm{rev}, \mathrm{a}_{\mathrm{p}}=1,5 \mathrm{~mm}\right)$

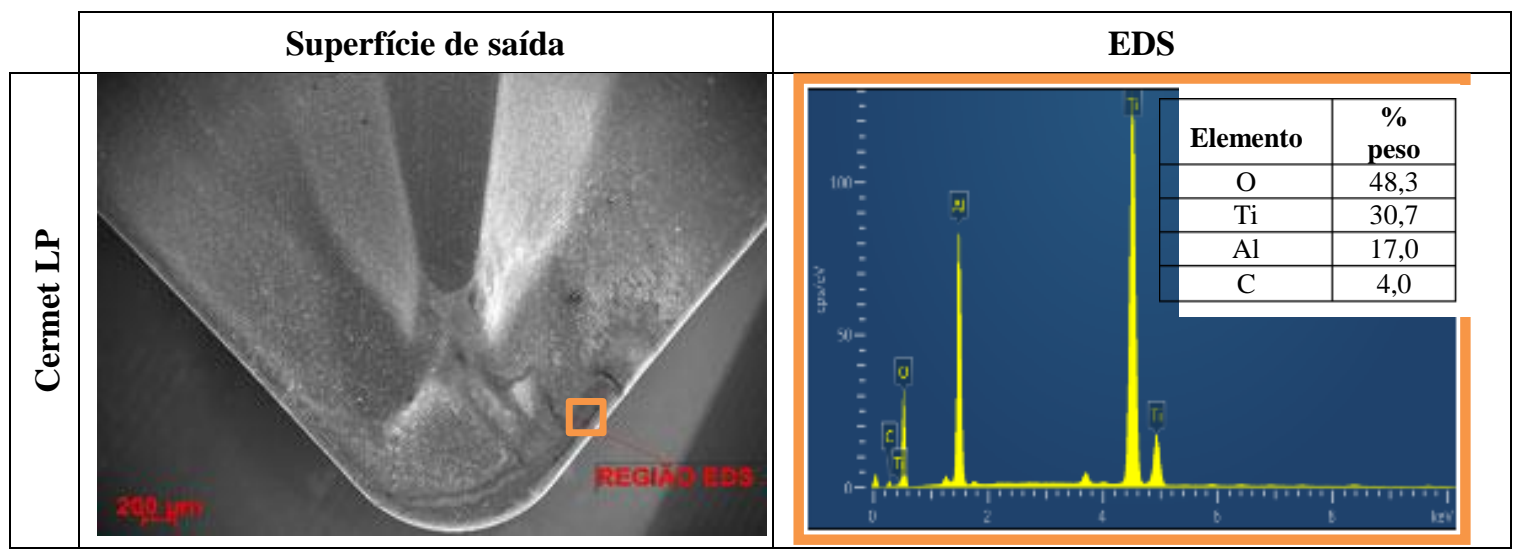




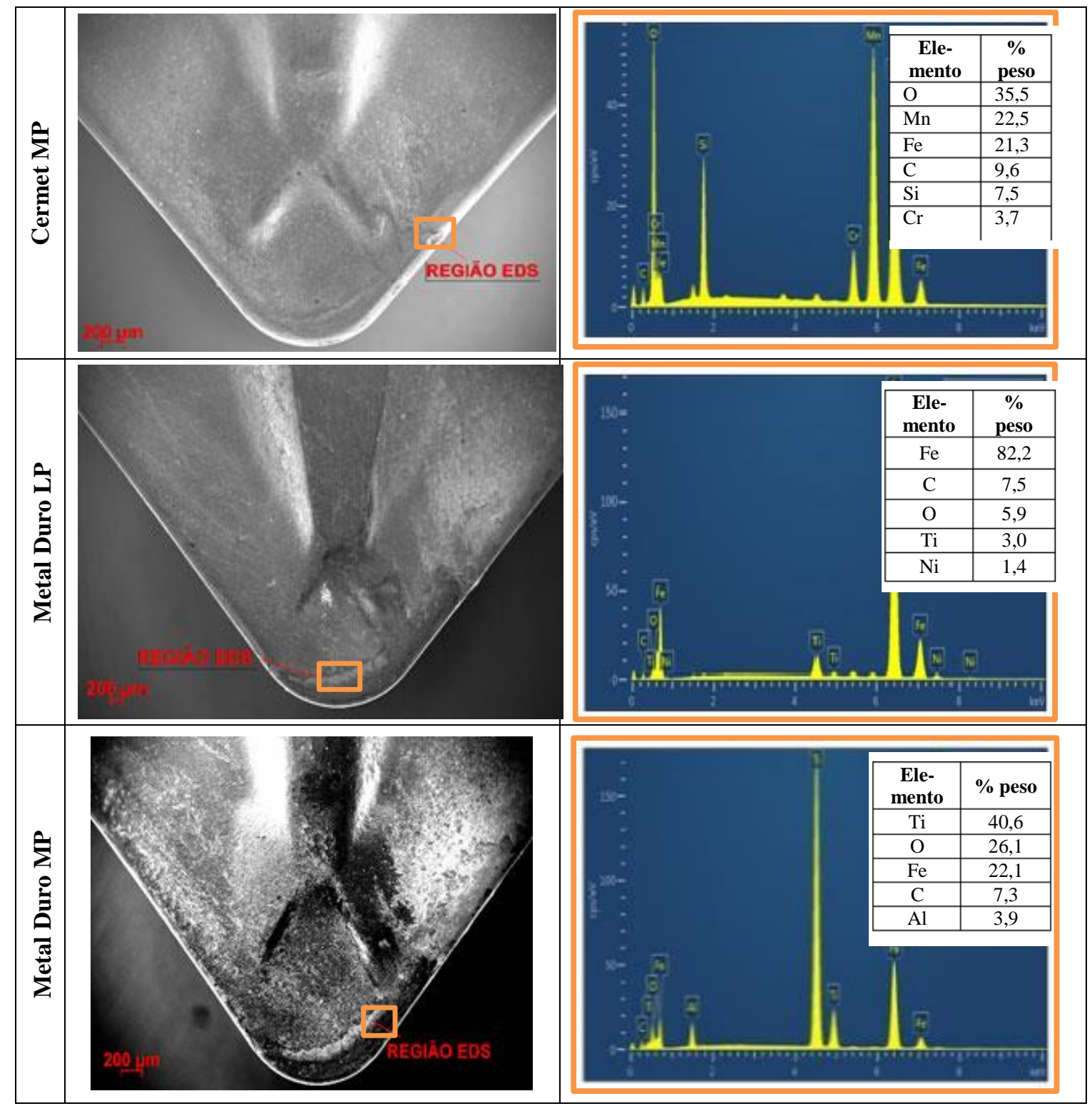

As imagens caracterizam regiões da superfície de saída onde estiveram presentes possíveis zonas de aderência e escorregamento. A ocorrência dos elementos ferro, manganês, silício, enxofre, cromo, alumínio e carbono, todos presentes na composição química da amostra do aço ABNT 4340, elucida a adesão de material dos cavacos. Por fim, a Tabela 7 apresenta as imagens das superfícies de folga com as respectivas análises por EDS. 
Tabela 7: imagens das superfícies de folga dos insertos e análise EDS $\left(\mathrm{v}_{\mathrm{c}}=250 \mathrm{~m} / \mathrm{min}, \mathrm{f}=0,16 \mathrm{~mm} / \mathrm{rev}, \mathrm{a}_{\mathrm{p}}=1,5 \mathrm{~mm}\right)$

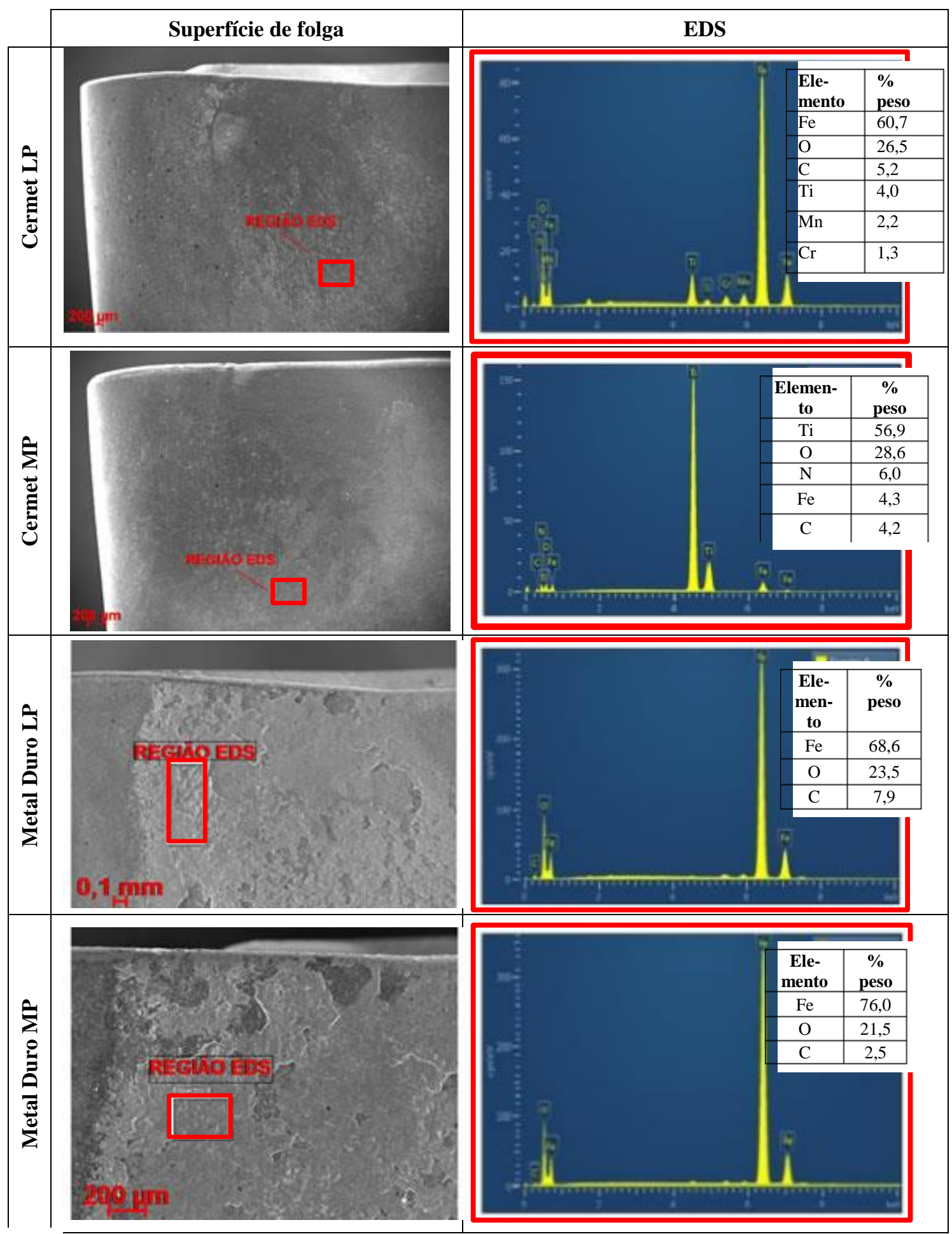

Em todas as análises de EDS, para as regiões em destaque, verificou-se a presença de ferro e oxigênio, fato que elucida a adesão de material do aço ABNT 4340, bem como a presença de óxidos. Para as superfícies de folga dos cermets, percebeu-se a presença de titânio, acreditando-se que pertença à camada do revestimento de TiN, sendo que a adesão ocorreu acima desta.

\section{DISCUSSÃO}

Considerando a resposta força de corte em relação à variável de entrada material da ferramenta de corte, mesmo o efeito principal sendo considerado significativo ao nível de confiança estudado, verificou-se uma 
curva levemente inclinada no gráfico de efeito principal. Os dados obtidos durante os ensaios, observou-se que os insertos de cermet apresentaram uma força de corte aproximadamente 5\% menor em relação aos valores obtidos pelos insertos de metal duro. DINIZ et al. [4] afirmam que, com a variação do material da ferramenta, ocorre uma pequena variação do coeficiente de atrito entre cavaco e superfície de saída da ferramenta, afetando de maneira pouco significativa a pressão específica de corte. Concomitante, há trabalho [12] mostrando que ao comparar uma ferramenta de cermet e uma de metal duro com camada de revestimento triplo TiCN-Al $\mathrm{O}_{3}$-TiN, a primeira ferramenta mostrou uma menor força de corte do que a ferramenta revestida, e à medida que o tempo de corte prolongou-se, a força de corte aumentou gradualmente para ambos insertos. Os autores relacionaram esse fato ao desgaste da ferramenta, ressaltando que, geralmente, a resistência ao desgaste dos materiais segue a sua própria dureza. No caso, a ferramenta de cermet mostrou menos desgaste do flanco do que a ferramenta revestida, nas curvas de desgaste para baixos valores de profundidade de usinagem. Esse fenômeno está relacionado à dureza do material, dado que o material cerâmico do substrato do cermet tem maior resistência quando comparado aos revestimentos do metal duro, ocasionando assim melhor resistência à delaminação. Retomando a análise de variância descrita pela Tabela 2, verificou-se que o efeito principal da geometria do quebra-cavaco sobre a força de corte, não foi significativo ao nível de confiança do modelo. Tal fato corrobora os estudos de MILLS E REDFORD [17], que afirmam quebra-cavacos do tipo anteparo, trabalhando sob condições normais de usinagem, quando comparados a superfícies de saída planas, não afetam significativamente as forças de usinagem. Por fim, observouse que, apesar do aumento do avanço sugerir uma diminuição da pressão específica de corte, maiores valores de avanço proporcionam aumento da área da seção de corte, ocasionando, por conseguinte, o aumento da força de corte.

Em relação a variável de entrada avanço, notou-se que a mudança de nível desta afeta consideravelmente a média de $\mathrm{R}_{\mathrm{q}}$ e conforme sumariza a Tabela 4 a ANOVA foi capaz de explicar 97,79\% da variação de $\mathrm{R}_{\mathrm{q}}$ corroborando a literatura [1-4] ao afirmar ser o avanço o parâmetro mais influente sobre o acabamento. SHAW [19] realça a atenção ao demonstrar, no torneamento do aço AISI 1045, com ferramenta de metal duro, o melhor acabamento não ocorrer para o menor valor de avanço $(0,05 \mathrm{~mm} / \mathrm{rev})$, mas para o valor de $0,1 \mathrm{~mm} / \mathrm{rev}$. O autor [19] explica esse fato por meio da energia de corte por unidade de volume e dos esforços que aumentam rapidamente sobre a face da ferramenta, quando o avanço é menor que $0,1 \mathrm{~mm} / \mathrm{rev}$, causando maior fluxo lateral a partir da borda de corte, ao longo da aresta de corte secundária, ou seja, o efeito escala. Nesse sentido, HUTCHINGS [20] afirma ser possível a ocorrência de sulcamento, em baixos níveis de avanço, aos quais o material é deformado e não removido, prejudicando a formação do cavaco.

Em relação à coloração, cavacos provenientes do avanço igual a $0,16 \mathrm{~mm} / \mathrm{rev}$ apresentaram coloração azul, e aqueles de $0,40 \mathrm{~mm} / \mathrm{rev}$, cor dourada. A cor azul está relacionada a uma fina camada de óxido que é formada poucos segundos após a constituição do cavaco na presença de maiores temperaturas. A justificativa para a coloração azul na condição de menor nível de avanço deve-se ao fato de a espessura do cavaco ser menor, o que fez com que este ficasse represado por um maior tempo e, assim, apresentasse maior oxidação. Este fato corrobora os estudos de outro trabalho [21] que, ainda acrescentam a necessidade de correlacionar a coloração dos cavacos à propriedade física de condutividade térmica, dado que o cermet apresenta cerca de $12 \%$ da condutividade do metal duro [3]. Nesse sentido, outros pesquisadores [22] observaram que, insertos de metal duro com revestimento de TiN, apresentaram diferente coloração do cavaco no torneamento do aço AISI 4340, sendo a dourada até o tempo usinado de 10,1 min, em seguida a cor foi mudando gradualmente até atingir 19,48 min, predominando a coloração azulada. Esse fato foi atribuído a baixa condutividade térmica do revestimento de TiN, que indicou uma reduzida taxa de aumento da temperatura durante a usinagem com insertos de metal duro com esse revestimento.

Por fim, em relação à vida e ao desgaste de ferramentas, os estudos [17-18] mostraram que a vida está mais associada aos parâmetros de corte $\left(\mathrm{v}_{\mathrm{c}}\right.$, $\left.\mathrm{f} \mathrm{e} \mathrm{a}_{\mathrm{p}}\right)$ e de revestimento que ao material da ferramenta. Nesse sentido, ASTAKHOV [15] afirma que o desgaste da ferramenta não depende somente do tempo de corte ou do seu percurso, mas também da geometria da ferramenta (ângulo de saída, ângulos de inclinação, ângulo de folga, raio da ponta), regimes de corte (velocidade de corte, avanço e profundidade de usinagem), propriedades da peça (dureza, resistência à tração, tensão, por exemplo) presença e propriedades de fluidos de corte e muitos outros parâmetros do sistema de usinagem. Logo, para os parâmetros de corte utilizados neste trabalho, o tempo de usinagem não foi suficiente para observar critérios de fim de vida como determinado por norma [23], pois isso não foi o objetivo. 


\section{CONCLUSÕES}

Por meio dos resultados dos testes de torneamento do aço ABNT 4340, utilizando-se ferramentas de corte de metal duro e de cermet e parâmetros de corte estabelecidos neste experimento, são descritas algumas considerações. Em relação à força de corte, pode-se concluir que a aplicação do planejamento fatorial completo $2^{3}$ permitiu confirmar que os parâmetros principais, material da ferramenta de corte e avanço, e todas as interações de segunda ordem entre os efeitos principais do avanço, material da ferramenta de corte e quebra-cavaco, afetaram significativamente a força de corte. De maneira geral, o aumento do avanço elevou a força de corte, e o material de ferramenta de corte cermet garantiu as menores forças. Quanto à geometria do quebra-cavaco e suas interações com o avanço e o material da ferramenta de corte, os menores valores de força de corte, foram encontrados para a configuração MP.

Sobre à rugosidade da superfície torneada, constatou-se que o mesmo planejamento fatorial, aplicado anteriormente para a análise da força de corte, permitiu constatar que diferentes níveis de materiais de ferramenta ou quebra-cavacos não foram suficientes para alterar significativamente o valor de $\mathrm{R}_{\mathrm{q}}$. Relativo à forma do cavaco, conclui-se que, o aumento do avanço causou alteração na forma do cavaco, para os dois tipos de material da ferramenta e geometrias de quebra-cavaco estudados. Comparando-se espessura do cavaco e avanço, observou-se quanto menor o valor do avanço, menor é a espessura do cavaco, e quanto maior a espessura do cavaco, maior a sua fragmentação.

Para as condições de usinagem utilizadas neste trabalho e com as imagens obtidas por meio de miscroscopia eletrônica de varredura não foi possível afirmar a ocorrência de desgaste nas ferramentas de corte utilizadas, e ainda detalhar os possíveis mecanismos de desgaste. Verificou-se adesão de material da peça de aço ABNT 4340, tanto na superfície de saída quanto na superfície de folga, para os dois insertos.

\section{AGRADECIMENTOS}

Os autores desta pesquisa agradecem a assistência do Departamento de Engenharia Mecânica da Universidade Federal de Minas Gerais (UFMG) pela disponibilização do Laboratório de Usinagem e Automação. Agradecem, também, ao Instituto Politécnico (IPUC) da Pontifícia Universidade Católica de Minas Gerais pela disponibilização do microscópio eletrônico de varredura. À Capes e ao CNPq pelo financiamento desta pesquisa.

\section{BIBLIOGRAFIA}

[1] GRZESIK, W., Advanced Machining Processes of Metallic Materials: theory, modelling and applications, 2 ed., United States, Elsevier, 2017.

[2] KLOCKE, F., Manufacturing Processes 1: Cutting, RWTH ed., Germany, Springer, 2011.

[3] MACHADO, A. R., ABRÃO, A. M., COELHO, R. T., et al., Teoria da Usinagem dos Materiais, 3 ed., São Paulo, Blucher, 2015.

[4] DINIZ, A.E., MARCONDES, F.C., COPPINI, N.L., Tecnologia da Usinagem dos Materiais, 8 ed., São Paulo, Artliber, 2013.

[5] RAJABI, A., GHAZALI, M. J., DAUD, A. R., "Chemical composition, microstructure and sintering temperature modifications on mechanical properties of TiC-based cermet : a review", Journal of Materials and Design, v. 67, n.1, pp. 95-106, Feb. 2015.

[6] KUMAR, B. V. M., KUMAR, J. R., BASU, B., "Crater wear mechanisms of TiCN-Ni-WC cermets during dry machining", Journal of Refractory Metals and Hard Materials, v.25, n.5, pp. 392-399, Nov. 2007.

[7] YANG, T., NI, L., ZHENG, Q., et al., "Cutting wear, microstructure and mechanical properties of (Ti0.5,W0.5)C-based cermet inserts containing Mo2C", International Journal of Refractory Metals and Hard Materials, DOI: 10.1016/j.ijrmhm.2017.07.011, Jul. 2017.

[8] SHANKAR, E., BALASIVANANDHA PRABU, S., "Microstructure and mechanical properties of Ti $(\mathrm{C}, \mathrm{N})$ based cermets reinforced with different ceramic particles processed by spark plasma sintering", $\mathrm{Ce}$ ramics International, v.43, n.14, pp. 10817-10823, Oct.2017. 
[9] WOONG OH, S.,YONGAHN, S., SIKOH, K., et al., "Investigation into the microstructure and cutting performance of $(\mathrm{Ti}, \mathrm{Ta}, \mathrm{W})(\mathrm{CN})-\mathrm{Co} / \mathrm{Ni}$ cermets", International Journal of Refractory Metals and Hard Materials, v. 53, Part A, pp. 36-40, Nov.2015.

[10] HU, H.P., CHENG, Y., YIN, Z.B., et al., "Mechanical properties and microstructure of Ti(C, N) based cermet cutting tool materials fabricated by microwave sintering", Ceramics International, v. 41, n.10 part B, pp.15017-15023, Dec. 2015.

[11] ANTHONY, X.M. "Analysis of cutting force and chip morphology during hard turning of AISI D2 steel”, Journal of Engineering Science and Technology, v. 10, n.3, pp.282-290, 2015.

[12] CHEN, X., XU, J., XIAO, Q., "Cutting performance and wear characteristics of Ti(C,N)-based cermet tool in machining hardened steel”, Journal of Refractory Metals and Hard Materials, v. 52, n.1, pp. 143150, Sep. 2015.

[13] ZOU, B., ZHOU, H., CHUANZHEN, H., et al., "Tool damage and machined-surface quality using hot-pressed sintering $\mathrm{Ti}(\mathrm{C} 7 \mathrm{~N} 3) / \mathrm{WC} / \mathrm{TaC}$ cermet cutting inserts for high-speed turning stainless steels", The International Journal of Advanced Manufacturing Technology, v.79, n. 1-4, pp. 197-210, Jul. 2015.

[14] KEBLOUTI, O., BOULANOUAR, L., AZIZI, M.W., et al. "Modeling and multi-objective optimization of surface roughness and productivity in dry turning of AISI 52100 steel using (TiCN-TiN) coating cermet tools", International Journal of Industrial Engineering Computations, v.8, p.71-84, 2017.

[15] ASTAKHOV, V. P., Tribology of Metal Cutting, 1.ed., Great Britain, Elsevier, 2006.

[16] ZHANG, H., TANG, S., YAN, J., et al., "Cutting performance of titanium carbonitride cermet tools", Journal of Refractory Metals \& Hard Materials, v. 25, n.5-6, pp. 440-444, Nov. 2007.

[17] GONZÁLEZ, L.W.H., PÉREZ-RODRÍGUEZ, R., ZAMBRANO-ROBLEDO, P., et al., "Estudio del desgaste del flanco de carburos recubiertos y cermet durante el torneado de alta velocidad en seco del acero AISI 1045", Revista de Metalurgia, v. 47, n.3, pp. 262-272, Jun.2011.

[18] MILLS, B., REDFORD, A.H., Machinability of Engineering Materials. 1 ed., England, Applied Science Publishers, 1983.

[19] SHAW, M. C., Metal Cutting Principles, 1ed, New York, Oxford University Press, 1997.

[20] HUTCHINGS, I. M., Tribology: friction and wear of engineering materials, 2 ed., United Kingdom , Elsevier, 2017.

[21] DAS, A., MUKHOPADHYAY , A., PATEL, S.K., et al. "Comparative Assessment on Machinability Aspects of AISI 4340 Alloy Steel Using Uncoated Carbide and Coated Cermet Inserts During Hard Turning", Arabian Journal for Science and Engineering, pp. 1-22, 2016.

[22] SAHOO, A., K., SAHOO, B., "Experimental investigations on machinability aspects in finish hard turning of AISI 4340 steel using uncoated and multilayer coated carbide inserts", Measurement, v. 45, n.8, p. 2153-2165, Oct.2012.

[23] ISO Standard 3685. Tool life testing with single - point turning tools. 2.ed. 1993.

[24] MITSUBISHI. Mitsubishi Tooling Technology Level 2, 2006.

[25] AÇOLÍVER. Análise química do pedido: aço ABNT 4340, 2016.

\section{ORCID}

Bárbara Cristina Mendanha Reis Natália Fernanda Santos Pereira Anderson Júnior dos Santos Marcelo Araújo Câmara Paulo Eustáquio Faria Paulo César de Matos Rodrigues Juan Carlos Campos Rubio https://orcid.org/0000-0002-3266-0113 https://orcid.org/0000-0001-9686-8573 https://orcid.org/0000-0002-5285-3289 https://orcid.org/0000-0003-0617-9163 https://orcid.org/0000-0001-8169-4101 https://orcid.org/0000-0001-6386-6029 https://orcid.org/0000-0001-6187-6442 